\title{
The Transduction of Host-Guest Interactions into Electronic Signals by Molecular Systems **
}

\author{
Sensors \\ ISFETS and CHEMFETs \\ Polysiloxanes \\ Reference FETs \\ Polymer Membranes
}

\section{By David N. Reinhoudt * and Ernst J. R. Sudhölter}

Synthetic receptor molecules that selectively bind charged guests can store chemical information. The transduction of this information into electronic signals connects the chemical and electronic domains. Field effect transistors (FETs) are attractive transducing elements because these microdevices are able to register and amplify chemical changes at the gate oxide surface of the semiconductor chip.

Integration of molecular receptors and field effect transistors into one chemical system gives a device that can communicate changes of substrate activities in aqueous solution. Simulations of a system in which the receptor molecules are directly attached to the FET gate oxide indicate serious limitations with respect to sensitivity, dynamic range and extreme requirements for complex stability. Therefore we have concentrated on the integration of covalently attached thin membranes.

The problem of the thermodynamically ill-defined oxidemembrane interface has been solved by applying a covalently linked hydrophilic polyhydroxyethylmethacrylate (polyHEMA) gel between the sensing membrane and the silylated gate oxide. A buffered aqueous electrolyte solution in the hydrogel renders the surface potential at the gate oxide constant via the dissociation equilibrium of the residual silanol groups. The subsequent attachment of a polysiloxane membrane that has the required dielectric constant, glass transition temperature $T_{\mathrm{g}}$, and receptor molecule, provides a stable chemical system that transduces the complexation of cationic species into electronic signals (CHEMFET).

The response to changing $\mathrm{K}^{\oplus}$ concentrations in a solution of 0.1 $\mathrm{M} \mathrm{NaCl}$ is fast $(<1 \mathrm{sec})$ and linear in the concentration range of $10^{-5}-1.0 \mathrm{M}(55-58 \mathrm{mV} /$ decade). A reference FET (REFET) based on the same technology is obtained when the intrinsic sensitivity to changes in ion concentration is eliminated by the addition of $2.10^{-5} \mathrm{~mol} \mathrm{~g}^{-1}$ of didodecyldimethyl-

[*] Prof. D. N. Reinhoudt, Dr. E. J. R. Sudhölter

Department of Chemistry, University of Twente

P.O. Box 217, 7500 AE Enschede (The Netherlands)

[**] The authors acknowledge the important contributions in this field made by Dr. A. y. A. Berg, Ir. P. D. v. d. Wal, Dr. M. Skowronska-Ptasinska, Dr. H. A. J. Holterman, Dr. M. L. M. Pennings, Dr. A. G. Talma and Mr. H. van $V$ ossen from our research group and would like to thank Prof. $P$. Bergveld for stimulating discussions. Financial support from the CME Twente, and the Netherlands Technology Foundation (STW), and the Technology Science Branch of the Netherlands Organization for the Advancement of Pure Research (NWO) is gratefully acknowledged. ammonium bromide to the ACE membrane. Differential measurements with a REFET/CHEMFET combination showed excellent linear $K^{\oplus}$ response over long periods of time.

All chemical reactions used are compatible with planar IC technology and allow fabrication on wafer scale.

\section{Introduction}

The discovery by Pedersen ${ }^{[1]}$ that synthetic macrocyclic polyethers form complexes with cationic guest species has tremendously stimulated the molecular design and organic synthesis of receptor molecules that selectively recognize charged, or even neutral guest molecules. ${ }^{[1]}$ Almost from the beginning, this "host-guest" [2a] or "supramolecular"[2b] chemistry has been associated with possible technological applications. Solid-liquid, ${ }^{[3]}$ and liquid-liquid ${ }^{[4]}$ extraction by these macrocyclic receptors as well as facilitated transport through (liquid) membranes ${ }^{[5]}$ were reported soon after the early synthesis and complexation studies. In these applications, the receptor molecule (selectively) recognizes the ionic guest and renders the solution properties of the complex different from the guest. Compared with biological receptors, the synthetic receptors are still relatively simple with regard to selectivity and efficiency of the molecular recognition process, although their chemical synthesis may be very advanced. In biological processes the recognition process itself is often only the first step which is followed by a chemical reaction (enzymes) or by the transfer of the information from the molecular to the macroscopic level (signal generation and transmission). Consequently an important goal in supramolecular chemistry for the next decade will be to generate molecular systems ${ }^{[6]}$ containing receptor molecules that are able to transduce chemical interactions at the molecular level to observable physical quantities at the macroscopic level. Current work in the areas of self-assembled molecules like micelles, vesicles and organized monolayers is closely related to this objective. ${ }^{[7]}$

Far reaching ideas to extend the actual supramolecular chemistry to much larger assemblies of self organized molecules, have been outlined by $L e h n^{[2 b]}$ in terms of 
nanochemistry $\left(10^{-9}-10^{-7} \mathrm{~m}\right)$. He proposes that, among others, molecular electronics and molecular ionics could be developed in order to create molecular systems that are able to transfer and to store information via chemical interactions which are transduced into electronic or optical signals. The development of such molecular systems requires a growth process from the molecular to the macroscopic "molecular material" ${ }^{[8]}$ level.

We are following an alternative route to reach such molecular systems by integration of synthetic receptor molecules with semiconductor chips. This approach is based on our increasing ability to manufacture devices at the sub-micron level $\left(\geq 3.5 \cdot 10^{-7} \mathrm{~m}\right) .{ }^{191}$ In this review we summarize our work aimed at the development of this approach to molecular systems that are able to transduce specific host-guest interactions into "macroscopic" electronic signals. One of the "first generation" practical applications of our fundamental studies are accurate, functioning microsensors for the selective quantitative detection of cationic species in aqueous solutions.

As the transducing element we have chosen a field effect transistor, and for the sensing element we have used a variety of synthetic macrocyclic polyether receptor molecules and the natural ionophore valinomycin. The research described is focused on the integration of both elements in one molecular system ("molecular material") that can be regarded as a chemical entity with a designed function.

\section{Ion Sensitive Field Effect Transistors (ISFETs)}

The field effect transistor (FET) is able to measure the conductance of a semiconductor as a function of an electrical field perpendicular to the gate oxide surface. ${ }^{[10]}$ In the most simple form, a metal oxide field effect transistor (MOSFET), the device is a capacitive structure with an oxide layer as the insulator (Fig. 1 a). A positive charge on the metal (gate) induces a negative charge at the $\mathrm{SiO}_{2}$-Si semiconductor interface which results in a change of its lateral conductance a)

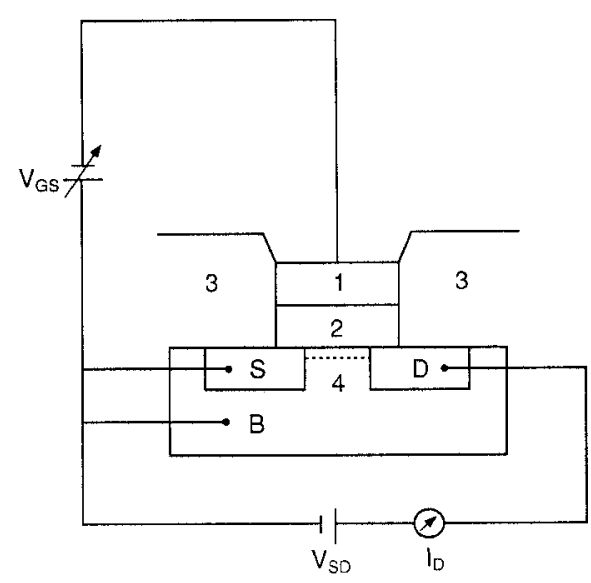

b)

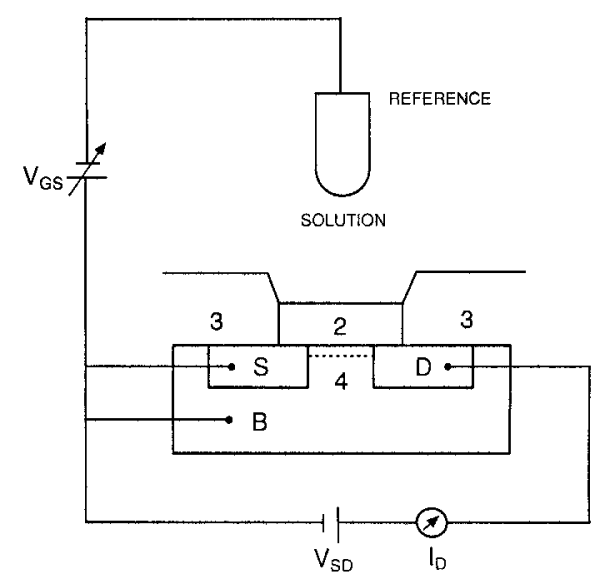

Fig. 1. Schematic representation of a MOSFET structure (a), and an ISFET structure (b). 1 : metal, 2 : gate oxide, 3 : insulating resin; 4 : channel, $S$ : source, D: drain, B: bulk.

(source-drain current) that can be measured between two contacts (source and drain). In 1970 Bergveld at the University of Twente removed the gate metal and placed the $\mathrm{SiO}_{2}$ gate oxide directly in an aqueous electrolyte solution (Fig. 1b). ${ }^{[1]} \mathrm{He}$ found that the source-drain current $I_{\mathrm{D}}$ is influenced by the interface potential at the oxide/aqueous

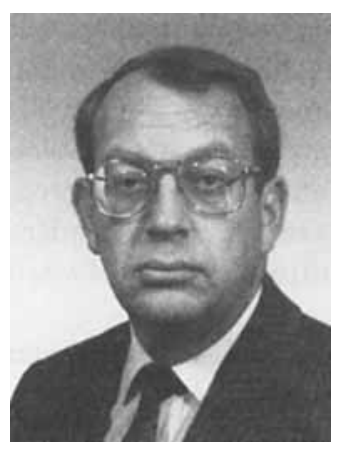

Professor David N. Reinhoudt was born in 1942 in the Netherlands. He studied Chemical Technology at the Delft University of Technology and gained a Ph.D. in chemistry in 1969 for his work with Professor H. C. Beijerman on a thesis entitled: "On the synthesis of Cephalosporin C". In 1970 he joined the Royal Dutch/Shell-Laboratories in Amsterdam as a research chemist in the department of Organic Chemistry. He was actively involved in the start-up of a novel group in "Heterocyclic Chemistry" at Shell and worked on thiepin chemistry and $(2+2)$-cycloadditions. In 1971 he started the crown ether research program at Shell and also worked on the physicalorganic chemistry of crown ether complexation. In 1978 he was appointed full professor at Twente University. His research interests include the synthesis of heterocycles with biological activity such as $\beta$-lactams and bioreductive anti-tumor antibiotics (Mitomycins), and pericyclic reactions. The major part of his research deals with the synthesis of macrocyclic host molecules, e.g. crown ethers, calixarenes, and (hemi)spherands, complexation studies with neutral guest molecules and the application of macrocycles in catalysis, membrane transport, and in (electronic) sensor systems. 
solution. Since $\mathrm{SiO}_{2}$ was used as the insulator, the chemical nature of the interface oxide is reflected in the measured source-drain current. Consequently this microchip transduces chemical information into an electronic signal and connects directly the chemical and the electronic domains. For the MOSFET structure (Fig. 1 a) it follows from first order MOS theory that Equation 1 holds, ${ }^{[12]}$ if $V_{\mathrm{SD}}<$ $V_{\mathrm{GS}}-V_{\mathrm{T}}$ ("unsaturated region") where: $I_{\mathrm{D}}=$ drain current; $\mu=$ electron mobility in channel; $C_{\mathrm{Ox}}=$ oxide capacity per unit area; $W / L=$ ratio of channel width to length; $V_{\mathrm{GS}}=$ gate-source potential; $V_{\mathrm{T}}=$ threshold voltage; $V_{\mathrm{SD}}=$ source-drain potential.

$I_{\mathrm{D}}=\mu \cdot C_{\mathrm{OX}} \cdot W / L \cdot\left[\left(V_{\mathrm{GS}}-V_{\mathrm{T}}\right) \cdot V_{\mathrm{SD}}-1 / 2 V_{\mathrm{SD}}^{2}\right]$

In the ISFET structure (Fig. 1 b) there are two additional potentials present; at the reference electrode-electrolyte solution interface $\left(E_{\text {ref }}\right)$ and a potential over the electrolyteinsulator interface $\left(X_{\text {sol }}-\psi_{0}\right)$. Both potentials replace the metal work function contribution $\left(\Phi_{\mathrm{M}} / q\right)$ in the equation for the drain current. The metal work function is part of the threshold voltage $V_{\mathrm{T}}$. This results in an expression for $I_{\mathrm{D}}$ shown in Equation 2, where: $\Phi_{\mathrm{Si}}=$ silicon work function; $Q_{\mathrm{it}}=$ trapped interface charge per unit area; $Q_{\mathrm{f}}=$ fixed oxide charge per unit area; $Q_{\mathrm{B}}=$ bulk depletion charge per unit area; $\Phi_{\mathrm{f}}=$ Fermi potential difference between bulk doped silicon and intrinsic silicon, and $q=$ elementary charge.

$$
\begin{aligned}
I_{\mathrm{D}}= & \mu \cdot C_{\mathrm{OX}} \cdot W / L \cdot\left(V_{\mathrm{GS}}-E_{\mathrm{ref}}+\psi_{0}-\chi_{\mathrm{sol}}\right. \\
& \left.+\frac{\Phi_{\mathrm{Si}}}{q}+\frac{Q_{\mathrm{it}}+Q_{\mathrm{f}}}{C_{\mathrm{OX}}}+\frac{Q_{\mathrm{B}}}{C_{\mathrm{OX}}}-2 \Phi_{\mathrm{f}}\right) \cdot V_{\mathrm{SD}}-1 / 2 V_{\mathrm{SD}}^{2}
\end{aligned}
$$

A change of $\mathrm{pH}$ in the electrolyte solution changes the $\mathrm{SiO}_{2}$ surface potential $\psi_{0}$. For a detailed description, the reader is referred to the literature. ${ }^{[12]}$ Yates et al. ${ }^{[13]}$ developed a theoretical site-dissociation model that describes the signal transduction as a function of the state of ionization of the amphoteric surface $\mathrm{SiOH}$ groups. The model was applied to ISFETs by Siu and Cobbold ${ }^{[14]}$ and Bousse. ${ }^{[15]}$ Later the model was extended to describe surfaces composed of two types of sites, and a typical $\mathrm{pH}$ response measured with $\mathrm{SiO}_{2}$ ISFETs is $37-40 \mathrm{mV} / \mathrm{pH}$ unit. ${ }^{[16]}$ We have chosen the ISFET as a transducing element because:

-The FET can be made very small with the available planar IC technology.

- The surface contains reactive groups for the (covalent) attachment of organic and biomolecules.

--In situ impedance transformation.

-Fast response time.

\subsection{Modification of the Oxide Surface of ISFETs}

The early work on ISFETs is associated with their application as a $\mathrm{pH}$ microsensor, particularly for biomedical pur- poses. ${ }^{[17]}$ One of the crucial problems for the further development of such micro sensors was the problem of a reference based on the same field effect principle, the so-called REFET, which should be insensitive to chemical changes in the electrolyte solution. This problem must be solved in all FET-based transductions of chemical interactions. Our work has concentrated on five major problems in the area of chemically modified ISFETs: 1 . Covalent coupling of organic matrices, with designed properties, to the ISFET surface gate oxide. 2. Development of a chemically inert reference based on FET technology. 3. Definition of thermodynamic equilibria at the interfaces. 4. Molecular design and organic synthesis of receptor molecules with high chemical selectivity. 5. Model description of the functioning of the chemically modified ISFET structure.

Modification of the $\mathrm{SiO}_{2}$ surface of ISFETs is a prerequisite in order to reduce or eliminate the $\mathrm{pH}$ sensitivity and to introduce organic functional groups for subsequent chemical modification by covalent linkages.

We found that silylation of the ISFET $\mathrm{SiO}_{2}$ surface changes the $\mathrm{pH}$ dependency of the surface potential (Fig. 2)

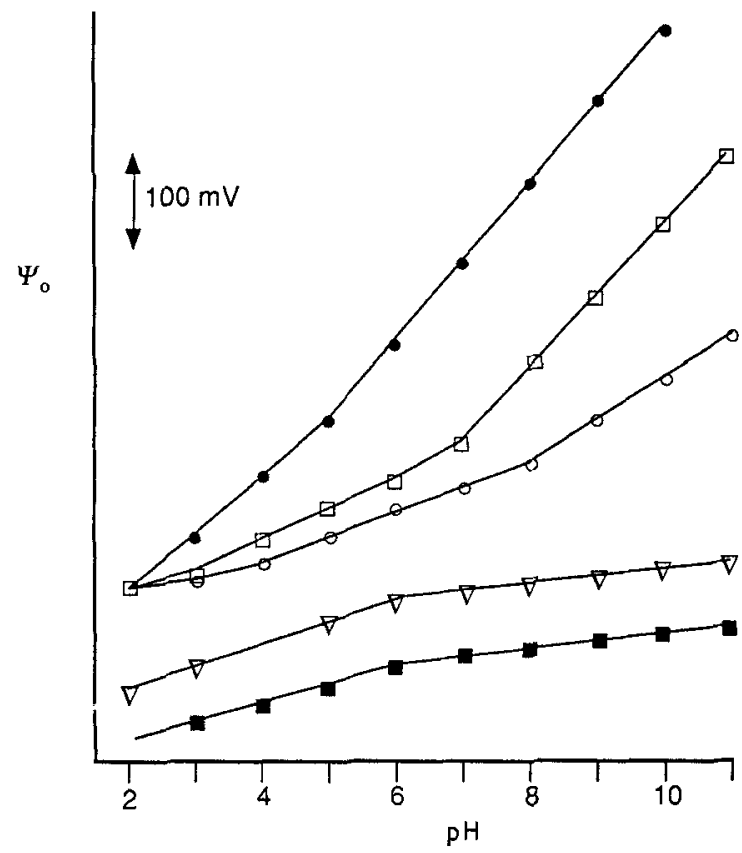

Fig. 2. Measured $\mathrm{pH}$ dependency of the surface potential $\psi_{0}$. Treatments: $\square$, none; o, thermal treatment $\left(500^{\circ} \mathrm{C}, 1 \mathrm{~h}\right) ; \nabla$, thermal treatment and reaction with trimethylchlorosilane; $\boldsymbol{\square}$, thermal treatment and reaction with hexamethyldisilazane; $\bullet$, reaction with 3 -aminopropyltriethoxysilane. For clarity the lines have been offset along the $\psi_{0}$-axis.

but does not completely eliminate the $\mathrm{pH}$ sensitivity. ${ }^{[16]} \mathrm{A}$ theoretical model confirms that a reduction of the original $\mathrm{SiOH}$ groups to less than $0.01 \%$ would be required. Consequently our work has focused on the covalent attachment of different thin polymeric layers to the surface. For chemical attachment, the surface was first silylated with 3- 
(trimethoxysilyl)propyl methacrylate. Subsequent copolymerization with vinyl monomers and vinyl prepolymers gives hydrophobic surfaces. As an alternative we have also reacted the surface with 3-(triethoxysilyl)propylamine followed by reaction with prepolymers of polyurethane that have isocyanato groups. These chemically linked polymers were compared with physically bound Vernis pour l'Electronique (VE) a polymer (mixture) that is often used as isolation coating in the electronics industry. The evaluation of the $\mathrm{pH}$ response showed that, except for the polyurethane and polybisacryl, all ISFETs exhibit a flat profile that indicates the almost complete coverage of the silanol groups (Fig. 3a).
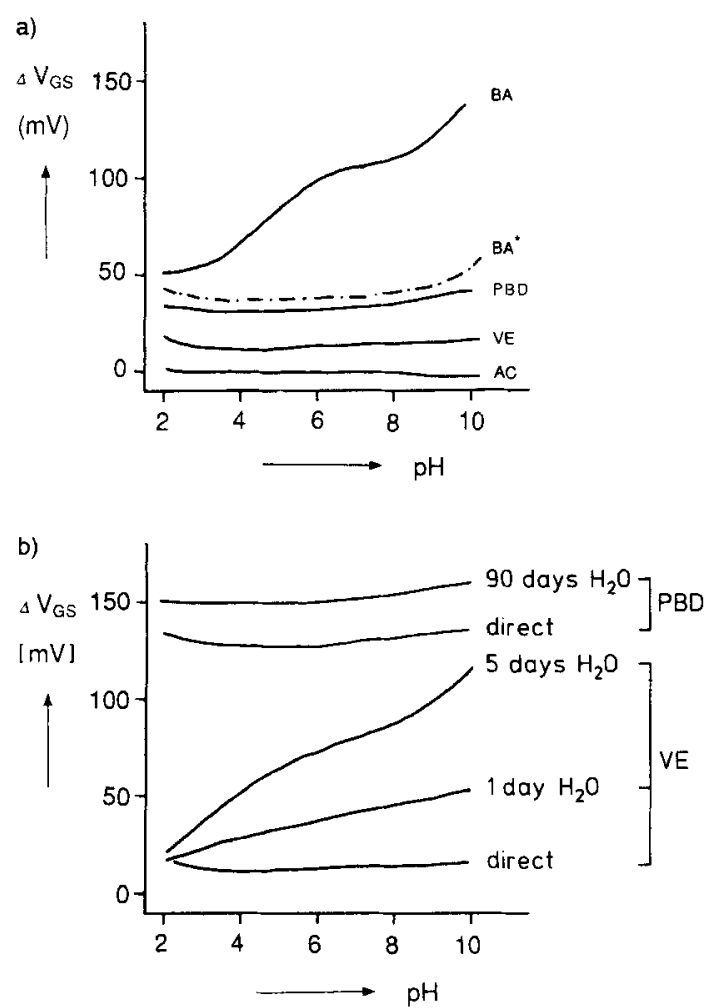

Fig. 3. pH Responses of modified ISFETs. (a) BA = bisacryl, BA* = bisacryl with added methacrylic acid, $\mathrm{PBD}=$ polybutadiene, $\mathrm{VE}=$ Vernis pour l'Electronique, $\mathrm{AC}=$ Mixture of $\mathrm{ACE}$ and Epocryl DRH 370 (meth)acrylates. (b) Influence of immersion time for physically bound VE and chemically bound PBD.

The difference between covalent chemical, and physical attachment was clearly demonstrated when the surfaces were continuously exposed to an aqueous electrolyte solution and evaluated in terms of their $\mathrm{pH}$ response at different time intervals (Fig. 3b). The physically attached layer of VE is already $\mathrm{pH}$ sensitive after one day, but the ISFETs with the chemically attached polybutadiene still show complete $\mathrm{pH}$ insensitivity after 90 days exposure. These results solve one of the major problems in the integration of FET transducers with molecular sensing elements. Such a chemically modified ISFET can in principle serve as a REFET. Further evalua- tion revealed that in several polymers e.g. polybutadiene, a slow process and/or $\mathrm{OH}^{-}$diffusion still takes place, resulting in an increased $\mathrm{pH}$ sensitivity upon long term exposure to acidic or basic solutions. The best results in these experiments were obtained with polyacrylates $(1, A C E)$ and polymethacrylates (2, Epocryl DRH 370 and 3, Bisacryl).

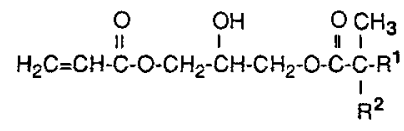

$$
R^{1}+R^{2}=C_{8} H_{18}
$$

1

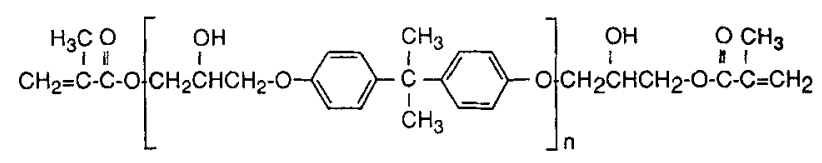

2

$$
\bar{n}=1.2
$$

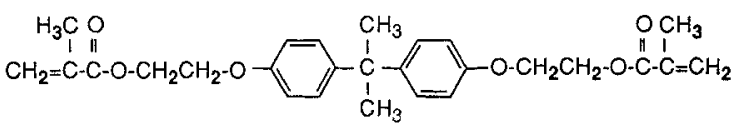

3

Scheme 1.

Although these polymer-modified surfaces are $\mathrm{pH}$ insensitive, for a reference system the sensitivity to other charged species must also be eliminated. In principle we can distinguish two situations, one in which ions can penetrate into the polymer layer (non-ion blocking) and one in which this is not possible (ion blocking). ${ }^{[18]}$ In the ion blocking structure, the observed potential of the REFET is a surface potential; in the non-ion blocking structure a membrane potential is formed, which is determined by the electrochemical thermodynamic equilibrium between ions in solution and in the polymeric membrane. The two structures have been distinguished by measuring the electrical relaxation time $\tau$, which is the time needed to redistribute charge and potential profiles in the polymeric membrane under the influence of an external electrical field. This relaxation time can be measured by various techniques such as transconductance measurements and light pulse response. ${ }^{[18]}$ We found that the bisacryl (BA) polymer had an ion blocking structure ( $\tau>10 \mathrm{~s}$ ) whereas relaxation times $<10 \mathrm{~s}$ for VE, PBD, and ACE modified REFETs correspond with a non-ion blocking structure. The presence of ions in the polymeric membrane was confirmed by independent secondary ion mass spectrometry (SIMS) experiments on PBD and BA before and after immersion in $10^{-3} \mathrm{M} \mathrm{KCl}$ solution for 2 hours. The SIMS profiles of cationic species in Figure $4 \mathrm{a}$ show that the uptake of $\mathrm{K}^{\oplus}$ ions by PBD is not observed for BA (Fig. 4 b). ${ }^{[19]}$ 

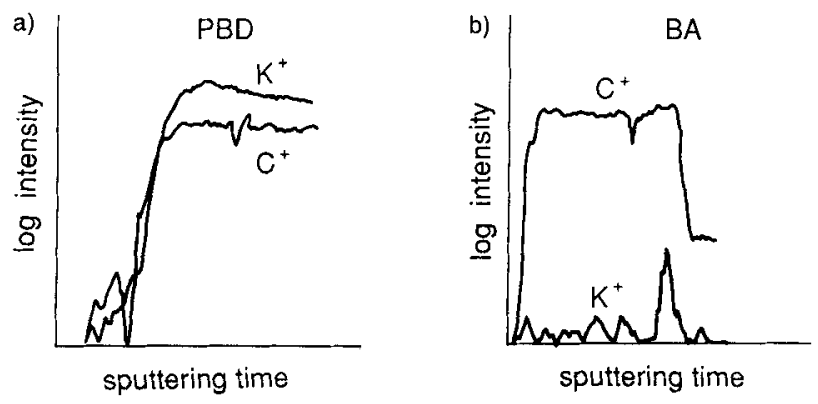

Fig. 4. Cationic SIMS profiles of a (a) non-blocking and a (b) blocking polymer. Both profiles were recorded after immersion in $10^{-3} \mathrm{M} \mathrm{KCl}$ for $2 \mathrm{~h}$.

The electrical relaxation time of ACE modified REFETs measured from bulk modulation $(\tau=0.35 \mathrm{~s})$ and light pulse response ( $\tau=0.40 \mathrm{~s}$ ) indicates the non-ion blocking structure. This will render this material, which satisfies best the requirements of $\mathrm{pH}$ insensitivity and long-term chemical stability, sensitive towards other ions. Permselectivity of polymeric membranes originates from the mobility differences of cations and anions. The presence of lipophilic anions in the membrane (which have a low mobility) therefore makes the membrane cation selective and vice versa. In order to suppress the observed cation permselectivity we have added lipophilic cations viz didodecyldimethylammonium bromide (DDMAB) to ACE prior to the in situ polymerization on the ISFET device. ${ }^{[18]}$ The resulting $\mathrm{K}^{\oplus}$ sensitivity of the various materials as shown in Figure 5 reveals that the initial permselectivity can be eliminated by the addition of $2.10^{-5} \mathrm{~mol}$ DDMAB per gram of ACE. Higher concentrations of

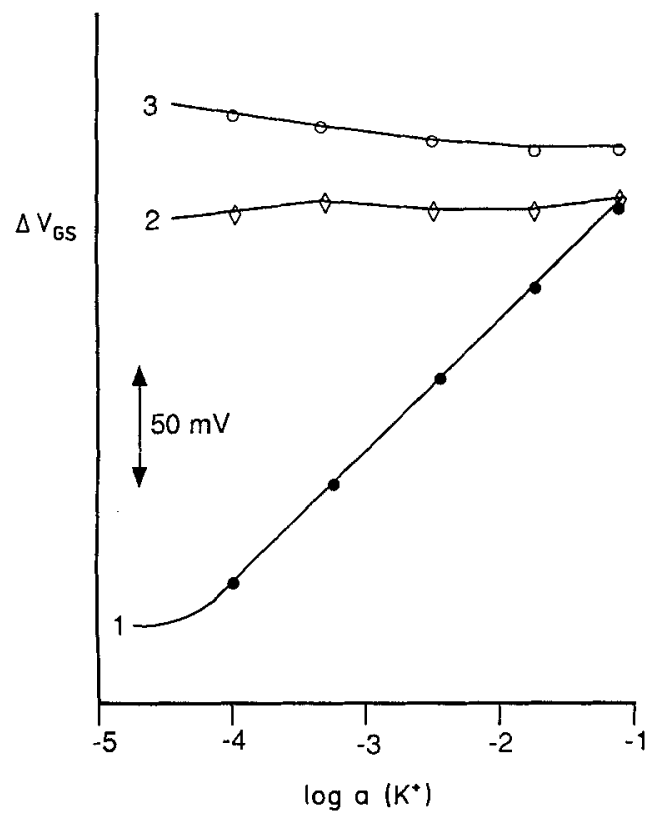

Fig. 5. Effect of the addition of various amounts of DDMAB to ACE on the concentration response of the ACE-REFETs. 1: [DDMAB] $=0 \mathrm{~mol} \mathrm{~g}^{-1} ; 2$ : $[D D M A B]=2.10^{-5} \mathrm{~mol} \mathrm{~g}^{-1} ; 3:\left[\right.$ DDMAB] $=9.10^{-5} \mathrm{~mol} \mathrm{~g}^{-1}$.
DDMAB renders these ISFETs anion selective because the material, with excess of lipophilic DDMA cations relative to the lipophilic anions present, acts as an anionic ionexchanger.

With this result we had achieved our first major objective, viz a reference sensor based on the same FET technology as the ISFETs. When we compare our system with REFETs reported in the literature the major difference is the covalent attachment of a non-ion blocking polymer to the transducing element. The first REFET reported by Matsuo ${ }^{[20]}$ is based on a physically attached ion blocking structure of parylene, coated on an $\mathrm{Si}_{3} \mathrm{~N}_{4}$ ISFET. This "REFET" showed a residual $\mathrm{pH}$ sensitivity of $10-30 \mathrm{mV}$ per decade and although this can be improved, there is a problem of intrinsic sensitivity to variations of electrolyte concentration. Similar attempts to cover ISFETs with relatively thick Teflon or plasmapolymerized styrene films suffer from a rapidly decreasing electrical sensitivity with increasing layer thickness. ${ }^{[21]}$ The applicability of our REFET system is clearly demonstrated in differential measurements with a $\mathrm{pH}$ sensitive ISFET. The schematic representation of such a differential measuring system is given in Figure 6a, with $\mathrm{Pt}$ as the quasi reference

a)

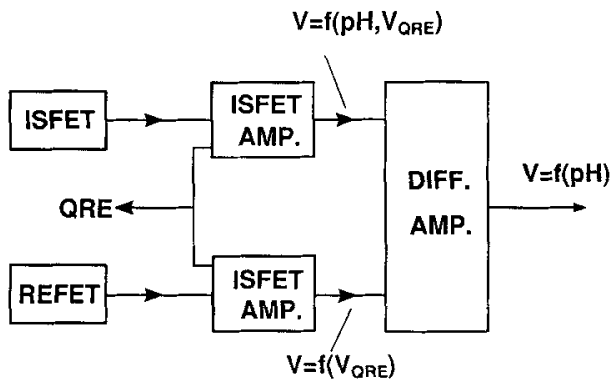

b)

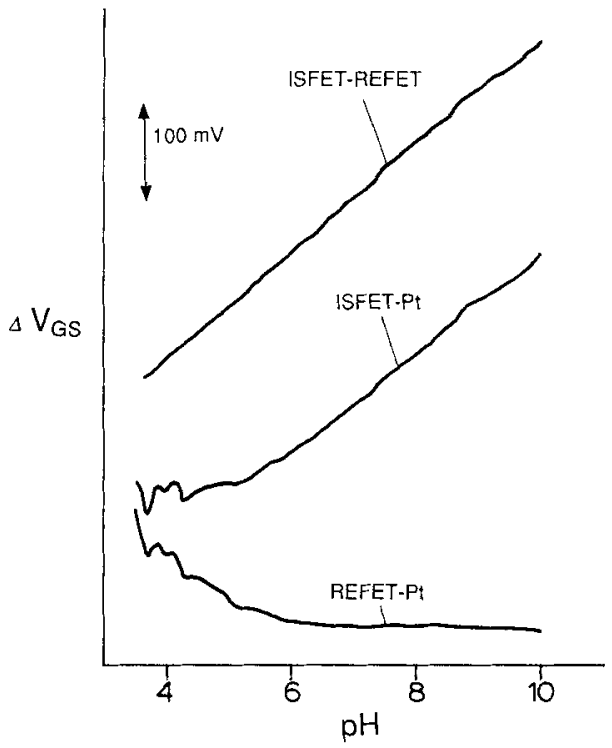

Fig. 6. a) Schematic representation of the differential measurement set up. QRE $=$ quasi reference electrode. b) Differential $\mathrm{pH}$ scan with an ACE modified ISFET ( = REFET) an $\mathrm{Al}_{2} \mathrm{O}_{3}$ ISFET and $\mathrm{Pt}$ as a quasi reference electrode. 
electrode, and the resulting $\mathrm{pH}$ response is shown in Figure 6b.

This set-up eliminates the thermodynamically undefined potential at the platinum-electrolyte interface (vide infra) and shows excellent linear response. ${ }^{[18]}$

\section{Chemically Sensitive ISFETs (CHEMFETs)}

Our work to develop molecular systems that transduce other than simple protonation/deprotonation reactions has taken advantage of ISFETs with physically attached membranes reported in the past decade. In 1975 Moss et al. ${ }^{[22]}$ reported a $\mathrm{K}^{\oplus}$-responsive ISFET. This device was obtained by attaching valinomycin-containing plasticized PVC membranes to the $\mathrm{SiO}_{2}$ gate. Although this system has the advantage of simplicity there are serious disadvantages. Firstly, there is no thermodynamically well-defined membraneISFET interface. Secondly, ionophore and other essential (vide infra) membrane components leach out of the membrane. Thirdly, a physically attached membrane has a limited lifetime. All systems that were reported when we started

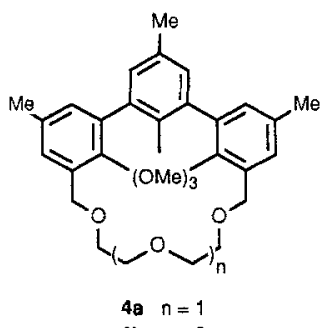

4b $n=2$

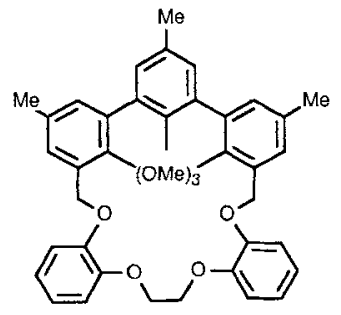

5

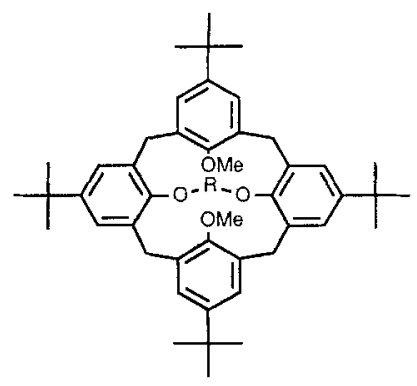

6 $\mathrm{R}=\mathrm{CH}_{2}\left(\mathrm{CH}_{2} \mathrm{OCH}_{2}\right)_{3} \mathrm{CH}_{2}$
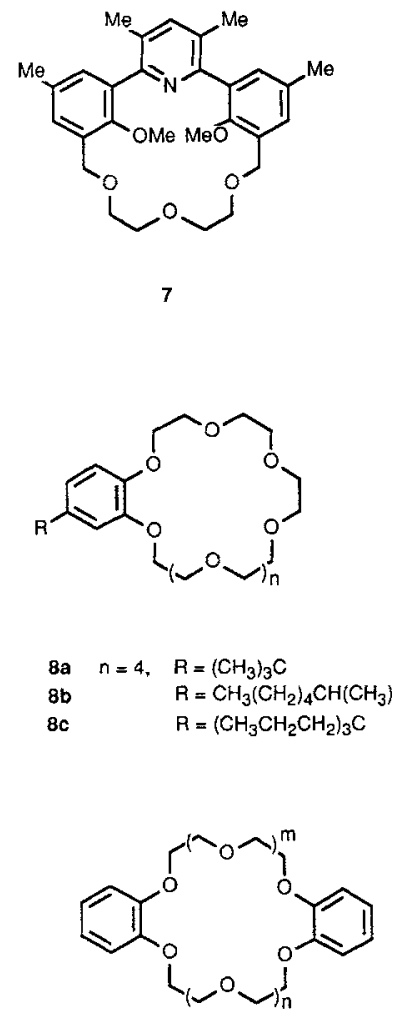

9a $n=m=1$

9b $n=m=2$

9c $n=5, m=1$
Scheme 2 . our work in this area suffered from one or more of these drawbacks.

Because, ultimately, the ionophore must be covalently linked to the organic matrix at the ISFET gate oxide, or extremely hydrophobic, we have synthesized hydrophobic receptors (4-9) that have both a sufficient $\mathrm{K}^{\oplus} / \mathrm{Na}^{\oplus}$ selectivity and can be chemically linked, which is not simply done with valinomycin. We found that both the hemispherands $(4 \mathbf{b}, 5)^{[23]}$ and the dimethylcalixcrown ether, $\mathbf{6}^{\left[{ }^{[23]}\right.}$ satisfy these conditions $\left(K_{\mathrm{a}}\left(\mathrm{Na}^{\oplus}\right) / K_{\mathrm{a}}\left(\mathrm{K}^{\oplus}\right) \leq 10^{-3}\right)$. The measured potentiometric selectivities, also recorded in plasticized $\mathrm{PVC}$, and the picrate extraction constants of the complexes in solution correlate well. ${ }^{[24]}$ This means that host-guest interactions at the molecular level can be selectively transduced to macroscopic signals.

Because the membrane-FETs (MEMFETs) based on physically attached PVC reported in the literature did not seem to suffer from the ill-defined interface between the sensing membrane and the semiconductor, virtually no experimental work to improve the system has been reported. However, Janata has expressed his concern ${ }^{[25]}$ and when Fogt et al. ${ }^{[26]}$ reported in 1985 the interference of $\mathrm{CO}_{2}$, the problem became fully recognized. Potential solutions, for example, an $\mathrm{Ag} / \mathrm{AgCl}$ intermediate layer to mask the silanol functionalities making the ISFET non-pH sensitive, generate novel problems with respect to the $\mathrm{AgCl}$-membrane interface potential. ${ }^{[27]}$ We have solved this $\mathrm{CO}_{2}$-interference problem in a way that the requirement of covalent chemical bonding is not violated. The silanol groups at the ISFET surface were partly covalently modified by reaction with methacryloxypropyltrimethoxysilane (MPTS, I, Scheme 3) into methacryl functionalities. Based on our previous work ${ }^{[28]}$ we assumed that coverage of silica with organo-functional silanes amounts to 1.5 functional groups per $\mathrm{nm}^{2}$ and consequently 3.5 silanol groups per $\mathrm{nm}^{2}$ surface, remain. These silanol groups will fix the surface potential of the ISFET, providing the local $\mathrm{pH}$ is constant. Subsequent (photo)copolymerization with monomeric hydroxyethylmethacrylate (HEMA, II, Scheme 3) covers the gate of the ISFET with covalently linked polyHEMA. ${ }^{[29]}$ Layer thicknesses between 5 and $15 \mu \mathrm{m}$ were reproducibly obtained and the photopolymerization is compatible with planar IC technology (Scheme 3).

Silylation of the silanol groups prior to photo(co)polymerization with HEMA is a prerequisite for the chemical stability of the resulting layers, as was shown in comparative experiments in aqueous solutions. ${ }^{[29]}$ Silylation in toluene ( $45 \mathrm{~min}$ ) gave results superior to gas phase silylation. The effect of the polyHEMA intermediate layer on the ISFET characteristics was evaluated after equilibration with a buffered $\mathrm{KCl}$ solution and application of the appropriate hydrophobic membrane on top. The most pronounced effect was the much improved stability of the signal (Table 1), in particular with polyacrylate membranes.

Due to the low uptake of water by such materials the proton (or hydroxide) exchange at the membrane-gate oxide surface will be slow. Impedance measurements, which are 
\begin{tabular}{c|c}
$\mathrm{c}$ & $\mathrm{OH}$ \\
$\mathrm{SiO}_{2}$ & $-\mathrm{OH}$ \\
& $-\mathrm{OH}$ \\
& $-\mathrm{OH}$ \\
& $-\mathrm{OH}$
\end{tabular}
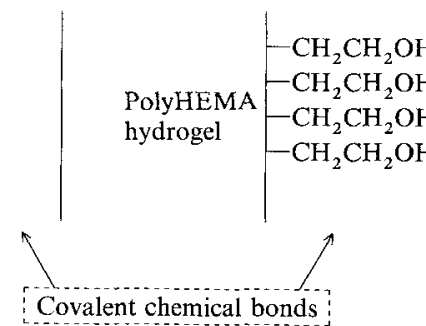

I $\quad(\mathrm{MeO})_{3} \mathrm{Si}\left(\mathrm{CH}_{2}\right)_{3} \mathrm{O}-\stackrel{\mathrm{O}}{\mathrm{U}} \stackrel{\stackrel{\mathrm{C}}{\mathrm{C}}-\stackrel{\mathrm{C}}{\mathrm{C}}=\mathrm{CH}_{2}}{\mathrm{CH}_{2}}$<smiles>C=C(C)C(=O)CCO</smiles>

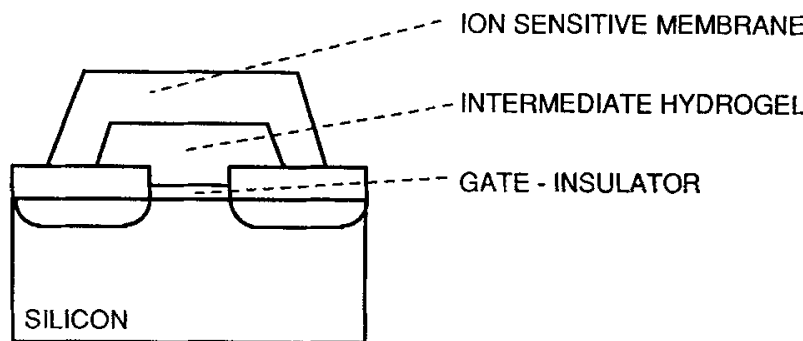

Scheme 3. CHEMFET structure. Top : the ISFET gate with surface $\mathrm{OH}$ groups (left), which are partially modified using $\mathbf{I}$ and II to produce a functionalized hydrogel (center), which in turn can be used to covaiently bond the polymer membrane (right) which contains the ion sensitive compounds. Bottom: schematic view.

not possible with directly attached acrylates, indicate a strongly reduced charge-transfer resistance $\left(R_{\mathrm{Cr}}\right)$ at the membrane inner interface.

Apart from much improved electrical properties, the intermediate buffered hydrogel layer also eliminates $\mathrm{CO}_{2}$ interference (Fig. 7). Because the hydrogel has hydroxyethyl functional groups, covalent anchoring of the hydrophobic membrane to the hydrogel is possible.

Table 1. Peak-to-peak voltages $\left(V_{p p}\right)$ of different modified ISFETs [a].

\begin{tabular}{lcc}
\hline & \multicolumn{1}{c}{$V_{\mathrm{pp}}[\mathrm{mV}]$} \\
\cline { 2 - 3 } Hydrophobic & $\begin{array}{l}\text { Without polyHEMA } \\
( \pm 0.01)\end{array}$ & $\begin{array}{c}\text { With polyHEMA [b] } \\
( \pm 0.005)\end{array}$ \\
\hline PVCmbrane & 0.10 & 0.030 \\
ACE/Epocryl DRH 370 [d] & $>10$ & 0.020 \\
Silopren [e] & 0.07 & 0.030 \\
Silicone rubber [f] & 0.10 & 0.040 \\
\hline
\end{tabular}

a) In the presence of $0.1 \mathrm{M} \mathrm{KCl}$, measured with a source and drain follower; b) Conditioned with $0.1 \mathrm{M} \mathrm{KCl}$, c) PVC-dioctylsebacate valinomycin; d) Poly(meth)acrylate membranes obtained from Shell; e) obtained from Bayer and containing valinomycin; f) Dow Corning RTV 3140 and containing valinomycin.

\section{New Materials for CHEMFETs}

Although the buffered intermediate polyHEMA layer solves the problem of the ill-defined thermodynamics of the ISFET-PVC membrane interface there are other problems

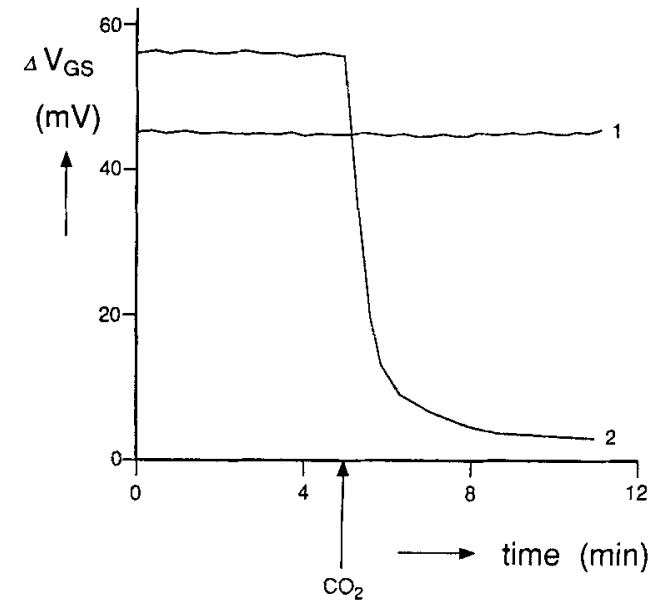

Fig. 7. Amplifier output voltage $\left(\Delta V_{\mathrm{GS}}\right)$ using $\mathrm{PVC}$ modified $\mathrm{SiO}_{2}$ ISFETs upon saturation of a $0.1 \mathrm{M}$ aqueous $\mathrm{KCl}$ solution with $\mathrm{CO}_{2}$. Curve 1 ; with a buffered $(\mathrm{pH}=4.0) 0.1 \mathrm{M} \mathrm{KCl}$ polyHEMA intermediate layer. Curve 2: PVC membrane directly deposited on the $\mathrm{SiO}_{2}$ gate oxide.

remaining, e.g. the high amount of external solvent mediator, and chemical inertness for covalent attachment of essential membrane components like ionophore and lipophilic anionic sites. The working mechanism of the plasticized PVC-type Ion Selective Electrodes has been extensively studied. ${ }^{[30]}$ From this work some general features for the design of the membrane materials can be defined:

-The membrane must be an elastomer (glass transition temperature $\leq 0^{\circ} \mathrm{C}$ ). For the currently used materials this is achieved by the addition of external solvent mediators.

-The membrane must be hydrophobic.

-For cation permselectivity, anionic sites e.g. tetraphenyl borate ${ }^{[31]}$ or surfactants ${ }^{[30]}$ must be present. These also lower the electrical resistance of the membrane.

For membranes applicable to ISFETs three additional conditions have to be met.

- Covalent linkage of the membrane to the ISFET gate oxide.

Compatibility with IC-technology which means that materials must be photopolymerizable.

-Covalent linkage of (all) membrane components e.g. plasticizing groups, anionic sites, and ionophore to the matrix.

On the basis of these conditions we have investigated acrylate and siloxane based materials. The (meth)acrylate based membrane materials were studied profoundly ${ }^{[31]}$ in order to achieve ion-selective FETs, since they showed excellent properties in their application to the preparation of REFETs (vide supra).

In all investigated cases the (meth)acrylate membrane was deposited on silylated and polyHEMA modified $\mathrm{SiO}_{2}$ ISFETs to define the interfacial thermodynamics. A schematic representation of the modified ISFET is displayed in Scheme 3.

In the absence of an ionophore the ACE membrane showed cationic permselective behavior of $44 \mathrm{mV} /$ decade. 
Addition of valinomycin did not introduce potassium selectivity, although in the absence of interfering ions the above mentioned permselectivity was still observed. This means that in the presence of interfering ions $(0.1 \mathrm{M} \mathrm{NaCl}$ on $0.1 \mathrm{M}$ $\mathrm{LiCl}$ ) no response was observed upon titration with $\mathrm{KCl}$. This prompted us to investigate the polymer system in more detail and we have varied the composition by changing the ACE:Epocryl monomer ratio, the type of external plasticizer, the acid number of $\mathrm{ACE}$, and the addition of the lipophilic anionic sites of potassium tetrakis(4-chlorophenyl)borate and the surfactant potassium dinonylnaphthalenesulfonate. Only occasionally could potassium selectivity be detected; however, after immersion of the modified ISFETs in aqueous electrolyte solutions overnight, the selectivity was always completely lost. Also, different chemical modifications of ACE did not result in a membrane material in which ionophores could introduce ion-selectivity.

In contrast to the (meth)acrylate membranes, the polysiloxanes studied can be deposited directly on the ISFET gate surface to give an adjustable modified ISFET. Of course, introduction of a polyHEMA interlayer will reduce the final noise level and also eliminate the interference of $\mathrm{CO}_{2}$ gas. ${ }^{[29]}$ The siloxane membranes formed have elastomeric properties and therefore they do not need an external plasticizer. For this reason these materials are very promising for the chemical modification of ISFETs. Good results were obtained by using DOW Corning RTV 3140 or Bayer Silopren siloxanes. Both materials have also been used in the preparation of conventional ion selective electrodes. ${ }^{[32]}$ In the presence of valinomycin or hemispherand ionophores, potassium selective chemical sensors have been prepared showing excellent performance. For instance, using diphenylhemisferand-21 in Silopren, a slope of $55 \mathrm{mV} / \mathrm{pK}^{\oplus}$ was observed and a potentiometric selectivity constant of $\log \mathrm{K}\left(\mathrm{K}^{\oplus}, \mathrm{Na}^{\oplus}\right) \approx-3.3$ was determined. Both materials show a good adhesion to the $\mathrm{SiO}_{2}$ gate oxide, probably originating from bond formation between surface silanol groups and the terminating hydroxy groups of the polysiloxanes.

Addition of tetrakis(4-chlorophenyl)borate to Dow Corning RTV 3140 increases the lifetime of the sensor from two to four weeks. For Silopren modified ISFETs a minor decrease of the slope to $54 \mathrm{mV} / \mathrm{pK}^{\oplus}$ was observed after eight weeks of continuous immersion in an electrolyte solution. Probably, electroactive components like ionophores and/or lipophilic anionic sites are leaching from the membrane.

\section{Photopolymerizable Siloxanes}

The success of the polysiloxanes as elastomeric materials in the preparation of potassium selective ISFETs stimulated us to design and synthesize new polysiloxanes, which can be crosslinked upon irradiation by UV light. Such materials are a prerequisite for the chemical modification of ISFETs on a wafer scale by using IC compatible technology. Therefore, random terpolymers have been synthesized by emulsion polymerization of octamethylcyclotetrasiloxane (D4), a mixture of the trimer and tetramer of (3-cyanopropyl)methylcyclosiloxanes ( $\mathrm{D}^{\prime} 3$ and $\left.\mathrm{D}^{\prime} 4\right)$, and methacryloxypropylmethyldichlorosilane (MS) (Fig. 8).
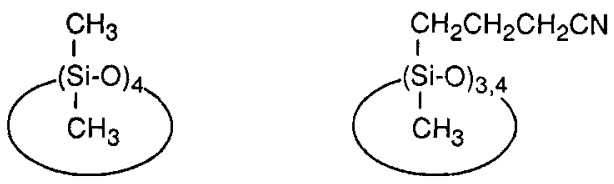

D4

$D^{\prime} 3+D^{\prime} 4$<smiles>C=C(C)C(=O)OCCC[Si](C)(Cl)Cl</smiles>

Fig. 8. Molecular structure of the D4. $\left(D^{\prime} 3+D^{\prime} 4\right)$ and MS building blocks in the synthesis of photopolymerizable siloxanes.

The relative amounts of the three different components have been varied. Increasing the cyanopropyl group content will increase the dielectric constant of the membrane, and increasing the methacryl group content will increase the glass transition temperature of the final membrane. A typical composition had the following molar ratio: $\mathrm{D} 4:\left(\mathrm{D}^{\prime} 3+\right.$ $\left.\mathrm{D}^{\prime} 4\right): \mathrm{MS}=10: 1: 2$. The material can be easily cross-linked using $4 \mathrm{wt}$. - \% of 2,2-dimethoxy-2-phenylacetophenone photoinitiator. Photo-crosslinking in the presence of valinomycin or diphenyl hemispherand-21 (5) ionophores and tetrakis(4-chlorophenyl)borate directly on the ISFET gate surface gave excellent potassium selective chemical sensors. ${ }^{[33]}$

\section{Modeling the Membrane Potential}

The developed potassium selective CHEMFET is, in essence, a potentiometric sensor. ${ }^{[34]}$ Variation of the primary ion activity in the electrolyte solution changes the membrane potential of the thin polymeric membrane covering the ISFET gate surface. The membrane potential is detected electronically by the ISFET, which acts as a potential transducer. The ion-selective membrane therefore connects the chemical domain with the electronic (semiconductor) domain. This is different from other FET based sensors in which a direct interaction between the ISFET gate oxide and the electrolyte solution is pursued.

Our current achievement in the development of ion-selective membranes, which have the electroactive components covalently bound to the membrane matrix which is sub- 
sequently covalently bonded to the ISFET gate surface, does not include the fixation of ionic sites and ionophores. ${ }^{[35]}$ In addition to experimental work, we have carried out simulations of the membrane potential as a function of physical parameters. ${ }^{[36]}$ The model used is an extension of the TeorellMeyer-Sievers model, but includes free and fixed ionic sites and neutral ionophores.

The presence of fixed anionic sites in the membrane leads to a negative boundary potential, which effectively prevents anions in the electrolyte solution from entering the membrane (Donnan exclusion). Immobilization of the neutral ionophore was simulated by gradually decreasing the mobility ratio $(\alpha)$ of cation-ionophore complex to free cation. This method is different from the system investigated by Morf ${ }^{[37]}$ in which an ion-exchange membrane was considered with fixed sites that have different association constants for different counterions. It was found that in such a system, no selective Nernstian response is to be expected. In our simulations we calculated that decreasing $\alpha$ results in a lower membrane response upon primary ion activity, which is caused by the development of a counteracting diffusion potential (Fig. 9).

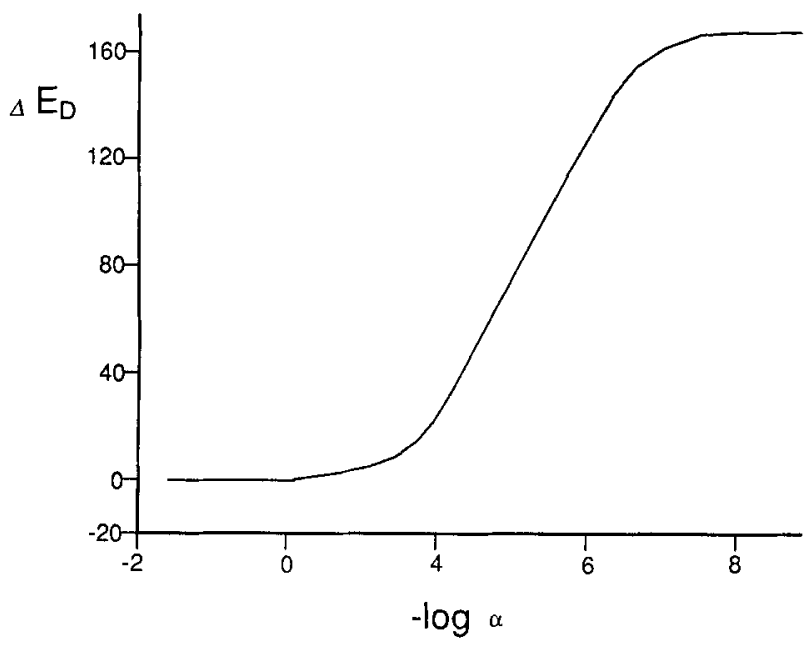

Fig. 9. Calculated diffusion potential build-up as a function of the complex/ cation mobility ratio $\alpha$.

From this Figure, three regions can be distinguished. At high $\alpha$ values there is no significant effect of $\alpha$ on the diffusion potential; in the linear region, reduction of $\alpha$ leads to a reduced diffusion potential and at very low $\alpha$ values a saturation region is present. In the linear region, the product of mobility and activity for the cation-ionophore complex is comparable to the same product for the free cation. Therefore, it is concluded that the free cations also contribute to the diffusion potential. The counteracting diffusion potential is absent if the product of cation-ionophore association constant, total ligand concentration and $\alpha$ is larger than $10^{4}$. In conclusion, the simulations show that complete immobiliza- tion of ionophore in a membrane having fixed anionic sites, results in a lower membrane potential when compared to the situation with mobile ionophores. High ionophore concentrations, and high complex association constants suppress this effect. For the design of ion-selective membranes having fixed ionophores, it will be necessary to bind the molecules via a spacer group to the polymer, giving them a small effective mobility.

\section{Conclusions}

Covalent attachment of a multi-layer membrane system in which receptor molecules are incorporated, to the gate oxide of a field effect transistor gives a molecular system (CHEMFET) that transduces chemical (complexation) reaction into electronic signals. A reference field effect transistor that is insensitive to the ionic strength of a solution is obtained when a specific amount of a lipophilic cation is incorporated in the sensing layer of the membrane.

The combination of these two devices, that can be integrated on one chip, allows the differential measurement of concentrations of cationic guest species in aqueous solution.

Received: October 2, 1989

[1] C. J. Pedersen, Angew. Chem. Int. Ed. Engl. 27 (1988) 1021; Angew. Chem 100 (1988) 1053.

[2] a) D. J. Cram, Angew. Chem. Int. Ed. Engl. 27 (1988) 1009; Angew. Chem. to0 (1988) 1041. b) J.-M. Lehn, Angew. Chem. Int. Ed. Engl. 27 (1988) 89; Angew. Chem. 100 (1988) 91.

[3] a) A. van Zon, F. de Jong, D. N. Reinhoudt, G. J. Torny: Chemicals in the Oil Industry, 2nd Int. Symp. on Chemicals in the Oil Industry, University of Manchester 1985, 241 . b) F. de Jong, A. van Zon, D. N. Reinhoudt, G. J. Torny, H. P. M. Tomassen, Recl. Trav. Chim. Pays-Bas 102 (1983) 164.

[4] Y. Takeda, Top. Curr. Chem. 121 (1984) 1.

[5] a) T. B. Stolwijk, P. D. J. Grootenhuis, P. D. van der Wal, E. J. R. Sudhölter, D. N. Reinhoudt, S. Harkema, J. W. H. M. Uiterwijk, L. Kruise, J. Org. Chem. 51 (1986) 489. b) T. B. Stolwijk, E. J. R. Sudhölter, D. N. Reinhoudt, J. van Eerden, S. Harkema, J. Org. Chem. 54 (1989) 1000. c) T. B. Stolwijk, E. J. R. Sudhölter, D. N. Reinhoudt, J. Am. Chem. Soc. 109 (1987) 7042.

[6] J.-M. Lehn, Science 227 (1985) 849

[7] C. D. Bain, G. M. Whitesides, Adv, Mater. 1989, 110; Angew. Chem. Int. Ed. Engl. Adv. Mater. 28 (1989) 506; Angew. Chem. Adv. Mater. 101 (1989) 522.

[8] J. Simon, J. J. André, A. Skoulious, New J. Chem. 10 (1986) 295.

[9] B. Santo, K. Wollard, IEEE Spectrum 25 (1988) 30.

[10] M. J. Madou, S. R. Morrison: Chemical Sensing with Solid State Devices, Academic Press, Boston 1989.

[11] P. Bergveld, IEEE Trans. Biomed. Eng. BME-17 (1970) 70.

[12] a) P. Bergveld, unpublished results. b) C. D. Fung, P.-W. Cheung, W. H. Ko, IEEE Trans, Electr. Dev. ED-33 (1986) 8.

[13] D. E. Yates, S. Levine, T. W. Healy, J. Chem. Soc. Faraday Trans, 70 (1974) 1807.

[14] W. H. Siu, R. S. C. Cobbold, IEEE Trans. Electron. Devices ED-26 (1979) 1805.

[15] a) L. Bousse: The Chemical Sensitivity of Electrolyte/Insulator/Semiconductor Structures (PhD Thesis). Enschede, The Netherlands (1982). b) L. Bousse, P. Bergveld, Sens. Actuators 6 (1984) 65.

[16] a) A. van den Berg, P. Bergveld, D. N. Reinhoudt, E. J. R. Sudhölter, Sens. Actuators 8 (1985) 129. b) J. F. Scherder, J. Colloid. Interface Sci. 61 (1987) 569 
[17] a) P. Bergveld, N. F. de Rooij: Monitoring of Vital Parameters During Extracorporeal Circulation, Proc. Int. Conf., Nijmegen, Netherlands (1980), 113. Karger, Basel 1981. b) P. Bergveld in W. H. Ko (Ed.): Implantable Sensors for Closed-Loop Prosthetic Systems, Ch. 8, Futura, Mount Kisco, N.Y., (1985).

[18] a) P. Bergveld, A. van den Berg, P. D. van der Wal, M. SkowronskaPtasinska, E. J. R. Sudhölter, D. N. Reinhoudt, Sens, Actuators 18 (1989) 309. b) M. Skowronska-Ptasinska, P. D. van der Wal, A. van den Berg, P. Bergveld, E. J. R. Sudhölter, D. N. Reinhoudt, Anal. Chim. Acta (1989) in press.

(19) A. van den Berg, P. D. van der Wal, M. Skowronska-Ptasinska, E. J. R Sudhölter, D. N. Reinhoudt, P. Bergveld, Anal. Chem. 59 (1987) 2827.

[20] a) T. Matsuo and M. Esashi, 153rd Mtg. Electrochem. Soc. Ext. Abstr. 78-1 (1978) 202. b) T. Matsuo. H. Nakajima, Sens. Actuators 5 (1984) 293.

[21] a) H. Nakajima, M. Esashi, T. Matsuo, J. Elektrochem. Soc. 129 (1982) 141. b) S. Tahara, M. Goshii, S. Oka, Chem. Lett. (1982) 307.

[22] S. D. Moss, J. Janata, C. C. Johnson, Anal. Chem. 47 (1975) 2238.

[23] E. J. R. Sudhölter, P. D. van der Wal, M. Skowronska-Ptasinska, A. van den Berg, P. Bergveld, D. N. Reinhoudt, Recl. Trav. Chim. Pays-Bas (1989) in press.

[24] a) P. J. Dijkstra, H. J. den Hertog Jr., B. J. van Steen, S. Zijlstra, M. Skowronska-Ptasinska, D. N. Reinhoudt, J. van Eerden, S. Harkema, $J$ Org. Chem. 52 (1987) 2433. b) P. J. Dijkstra, unpubiished results.

[25] J. Janata, Sens. Actuators 4 (1983) 255.

[26] E. J. Fogt, D. F. Untereker, M. S. Norenberg, M. E. Meyerhoff, Anal. Chem. 57 (1985) 1995.

[27] a) D. J. Harrison, L. Xizhong, E. M. J. Verpoorte, Proc. Transducers'87, Tokyo 1987, p. 738. b) L. Xizhong, E. M.J. Verpoorte, D.J. Harrison.
Anal. Chem. 60 (1988) 493. c) M. Dror, E. A. Bergs, R. K. Rhodes, Sens Actuators 11 (1987) 23

[28] E. J. R. Sudhölter, R. Huis, G. R. Hays, N. C. M. Alma, J. Colloid Interface Sci. 103 (1985) 554.

[29] E. J. R. Sudhölter, P. D. van der Wal, M. Skowronska-Ptasinska, A. van den Berg, P. Bergveld, D. N. Reinhoudt, Recl. Trav. Chim. Pays-Bas (1989) in press.

[30] a) M. L. Iglehart, R. P. Buck, G. Horvai, E. Pungor, Anal. Chem. 60 (1988) 1018. b) G. Horvai, K. Toth, E. Pungor, Anal. Chim. Acta 216 (1989) 163. c) R. D. Armstrong, M. Todd, J. Electroanal. Chem. 248 (1988) 131. d) R. D. Armstrong, A. K. Covington, W. G. Proud, I. Electroanal. Chem. 257 (1988) 155

[31] P. D. van der Wal, M. Skowronska-Ptasinska, A. van den Berg, P. Bergveld, E. J. R. Sudhölter, D. N. Reinhoudt, Anal. Chim. Acta (1989) in press.

[32] a) G. G. Guilbault, G. Nagy, Anal. Chem. 45 (1973) 417. b) H.-B. Jenny, C. Riess, D. Amman, B. Magyar, R. Asper, W. Simon, Microchim. Acta (Wien) (1980) II 390. c) I. A. Mostert, P. Anker, H.-B. Jenny, U. Oesch, W. E. Morf, D. Amman, W. Simon, Microchim. Acta (Wien) (1985) I 33.

[33] P. D. van der Wal, unpublished.

[34] E. J. R. Sudhölter, P. D. van der Wal, M. Skowronska-Ptasinska, A, van den Berg, D. N. Reinhoudt, Sens. Actuators 17 (1989) 189

[35] A. G. Talma, H. van Vossen, E. J. R. Sudhölter, J. van Eerden, D. N. Reinhoudt, Synthesis (1986) 680.

[36] A. van den Berg, P. D. van der Wal, M. Skowronska-Ptasinska, E. J. R. Sudhölter, P. Bergveld, D. N. Reinhoudt, unpublished results.

[37] W. E. Morf: The Principles of Ion Selective Electrodes and of Membrane Transport, Elsevier, Amsterdam 1981.

\section{E-MRS Strasbourg Conferences: (Symposia)}

Spring Meeting (May 29.-June 1. 1990)
A High- $T_{\mathrm{c}}$ Superconductor Materials
B Metal Matrix Composites
C Magnetic Thin Films, Multilayers
D Surface Modification and Coatings
E Surface Processing and Laser Assisted Chemistry

Fall Meeting (Nov. 27, -30.1990$)$

A Semiconductors in Optoelectronics

B Nonlinear Optical Materials

C Wide Band-Gap Semiconductors

D Characterization of Compound Semiconductors

Details from Prof. P. Siffert, B.P. 20, F-67037 Strasbourg Cedex (France), Tel. 8828 6543, Fax 88280990

\section{Call for Short Communications • Call for Short Communications $\cdot$ Call for Short Communications}
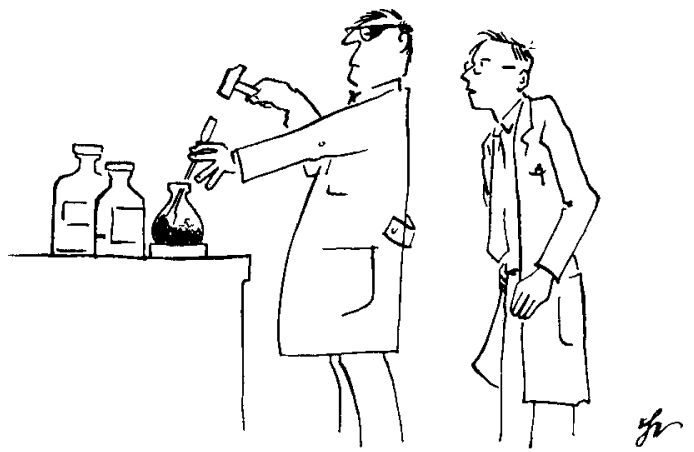

... doesn't melt, won't dissolve, just can't be broken down-let's send it to ADVANCED MATERIALS! 